\title{
Superagonistic Activation of ErbB-1 by EGF-related Growth Factors with Enhanced Association and Dissociation Rate Constants*
}

\author{
Published, JBC Papers in Press, June 5, 2000, DOI 10.1074/jbc.M004489200
}

\begin{abstract}
Anne E. G. Lenferink $\$$, Everardus J. J. van Zoelen $\neq$, Marianne J. H. van Vugt $\$$, Suzanne Grothe $\|$, Walter van Rotterdam $\$$, Monique L. M. van de Poll $\$$, and Maureen D. O’Connor-McCourt||

From the $\ddagger$ Department of Cell Biology, University of Nijmegen, Toernooiveld 1, 6525 ED Nijmegen, The Netherlands and the \|Biotechnology Research Institute, National Research Council Canada, Montreal H4P 2R2, Canada
\end{abstract}

\begin{abstract}
Epidermal growth factor (EGF) and transforming growth factor- $\alpha$ (TGF $\alpha)$ are mitogenic hormones that exert their activity primarily by binding to the EGF receptor, also known as ErbB-1. We have recently characterized a set of EGF/TGF $\alpha$ chimeric molecules with similar high affinity for ErbB-1 as EGF and TGF $\alpha$ and shown that three of these chimeras induce mitogenic cell stimulation at already a 10-fold lower concentration than their wild-type counterparts (Lenferink, A. E., Kramer, R. H., van Vugt, M. J., Königswieser, M., DiFiore, P. P., van Zoelen, E. J., and van de Poll, M. L. (1997) Biochem. J. 327, 859-865). In the present study we show that these so-called superagonistic chimeras do not differ from EGF and TGF $\alpha$ in their ability to induce ErbB-1 tyrosine phosphorylation but are considerably more potent in activation of mitogen-activated protein kinase phosphorylation. Direct cell binding studies and analysis of ligand-receptor interaction by surface plasmon resonance measurements revealed that both the association rate constant $\left(k_{\text {on }}\right)$ and the dissociation rate constant $\left(k_{\text {off }}\right)$ of these superagonists is $\mathbf{3 - 5}$-fold higher in comparison with the wild-type ligands and nonsuperagonistic chimeras. These data indicate that the dynamic on and off rate constants for receptor binding may be more specific parameters for determining the mitogenic activity of peptide hormones than their constants for equilibrium receptor binding.
\end{abstract}

Many polypeptide growth factors exert their action by binding to receptors with intrinsic tyrosine kinase activity (1). It has been well established that activation of such kinase activity following ligand binding is essential for the generation of intracellular second messengers and the subsequent control of cell proliferation (2). However, it is becoming more and more clear that the biological response of a ligand is not a mere reflection of its receptor binding properties, but the result of a complex interplay between receptor and ligand molecules both at the cell surface and inside the cell. This is particularly evident from studies on the epidermal growth factor (EGF) ${ }^{1}$ family of ligands, which induce their biological effects through

\footnotetext{
* The costs of publication of this article were defrayed in part by the payment of page charges. This article must therefore be hereby marked "advertisement" in accordance with 18 U.S.C. Section 1734 solely to indicate this fact.

$\S$ Supported by the Netherlands Organization of Scientific Research and Stichting De Drie Lichten during a stay at the Biotechnology Research Institute.

I To whom correspondence should be addressed. Tel.: 31-24-3652707; Fax: 31-24-365-2999; E-mail: vzoelen@sci.kun.nl.

1 The abbreviations used are: EGF, epidermal growth factor; TGF $\alpha$, transforming growth factor- $\alpha$; MAPK, mitogen-activated protein ki-
}

interaction with the ErbB family of receptor molecules (3).

EGF and transforming growth factor- $\alpha$ (TGF $\alpha)$ belong to the family of EGF-like growth factors that exert their action by interacting directly with the EGF receptor, also known as ErbB-1 (4). Ligand binding is rapidly followed by receptor dimerization, which is essential for the activation of the receptor's intrinsic tyrosine kinase activity. Dimerization may involve two identical ErbB-1 molecules but may also occur between the ligand-activated ErbB-1 receptor and one of the three other ErbB receptor family members, ErbB-2, ErbB-3, or ErbB-4. This receptor heterodimerization results in the recruitment of a broader spectrum of second messengers (1) and therefore in the activation of a more diverse panel of intracellular signaling pathways $(3,5)$.

Following ligand binding, the ErbB-1 receptor is rapidly internalized where it is inactivated as a consequence of ligand dissociation and degradation. However, recent data show that the ErbB-1 receptor is not only active at the cell surface but may still be actively signaling during internalization of the receptor-ligand complex $(6,7)$. As a consequence thereof, the fate of the internalized receptor may have direct consequences for the intensity of the growth factor-induced biological signal. It has been established that the EGF-ErbB-1 complex initially remains active within the cell immediately following internalization, after which it is rapidly degraded in the lysosomes. In contrast, the TGF $\alpha$-ErbB-1 complex is rapidly inactivated inside the cell because of dissociation of the ligand, allowing the ErbB-1 receptor to recycle to the plasma membrane where it can be reused by another ligand molecule (8). In contrast to ErbB-1, the other ErbB receptors are all impaired in their internalization (9), whereas in addition we and others have shown that both ErbB-2 and ErbB-3 can rescue ErbB-1 from lysosomal degradation by inducing recycling of the EGF-bound heterodimeric receptor complex $(10,11)$. In addition, there is an increasing awareness that EGF-like growth factors inside the cell may be targeted to the nucleus, which may also contribute to their biological activity $(12,13)$.

Mutant forms of EGF have been identified with only low ErbB-1 binding affinity that show similar dose-dependent mitogenic activity as wild-type EGF, particularly on cells overexpressing ErbB-1 (14-18). This shows that there is no direct correlation between the affinity of EGF-like growth factors and their mitogenic potential. The molecular basis for this phenomenon is still poorly understood but has been associated with reduced ligand proteolysis (14), high ErbB-1 expression levels (17), and routing of the receptor after ligand-induced internalization (18). We have recently characterized a set of chimeric

nase; SPR, surface plasmon resonance; h, human; m, murine; HPLC, high pressure liquid chromatography; BES, 2-[bis(2-hydroxyethyl)amino] ethanesulfonic acid; EGFR, epidermal growth factor receptor. 
molecules composed of EGF and $\mathrm{TGF} \alpha$, which all have similar binding affinity to ErbB-1 (19). Nonetheless, growth stimulation studies showed that three of them, designated E3T, E4T, and T3E4T, are able to induce a mitogenic response at already a 10 -fold lower concentration than wild-type EGF and TGF $\alpha$ (20).

In the present study we show on the basis of receptor tyrosine phosphorylation studies, mitogen-activated protein kinase (MAPK) phosphorylation experiments, in vitro ligand binding studies, and kinetic analysis of receptor-ligand interactions using surface plasmon resonance (SPR) measurements that, compared with EGF and $\mathrm{TGF} \alpha$, these so-called superagonists have both enhanced association and dissociation rate constants for binding to the ErbB-1 receptor. These data indicate that the on and off kinetics of ligand binding may represent an important additional parameter in determining the biological response of growth factor action.

\section{EXPERIMENTAL PROCEDURES}

Cellular Assays-NIH-3T3 cells transfected with the human (h) ErbB-1 receptor (a gift from Dr. J. Schlessinger, New York University) were used throughout this study. The so-called HER-14 cell line contains $4.0 \times 10^{5} \mathrm{hEGF}$ receptors/cell (21). Cells were cultured in Dulbecco's modified Eagle's medium supplemented with $10 \%$ newborn calf serum (Hyclone) using gelatinized flasks. Binding competition experiments using radiolabeled ligand and mitogenic assays on these cells were performed as described (20).

Ligand Production-Recombinant human EGF, TGF $\alpha$, and chimeras thereof were expressed as fusion proteins with protein A (ProtA) and subsequently affinity purified using IgG-Sepharose (Amersham Pharmacia Biotech) as described (19). The yield of purified fusion protein was determined in an enzyme-linked immunosorbent assay-like binding competition on IgG antibodies using biotin-labeled protein A as competitor (22), whereas the biological activity of the samples was determined in a binding competition assay with iodinated murine $(\mathrm{m})$ EGF on HER-14 cells (23). IgG-purified ProtA fusion proteins were used for SPR measurements as well as for cell growth and in vitro binding experiments, whereas HPLC-purified recombinant ligands devoid of the ProtA tag (23) were used for the receptor tyrosine phosphorylation and MAPK measurements. All HPLC-purified recombinant ligands showed similar specific activity for binding to HER-14 cells as mEGF from the natural source (23).

Mitogen-activated Protein Kinase Phosphorylation-Cells were grown to confluence in 6-well dishes $\left(9.8 \mathrm{~cm}^{2}\right.$; Nunc) and incubated for $48 \mathrm{~h}$ in $950 \mu \mathrm{l}$ of Dulbecco's modified Eagle's medium supplemented with $0.1 \%$ bovine serum albumin at $37^{\circ} \mathrm{C}$. Kinase assays were performed in two different settings. Dose-dependent experiments were carried out by adding serial dilutions of recombinant growth factors in $50 \mu \mathrm{l}$ of BES-buffered Dulbecco's modified Eagle's medium to serumstarved cells followed by a 5 -min incubation at $37^{\circ} \mathrm{C}$. Time-dependent experiments were carried out by adding recombinant growth factors at a final concentration of $10 \mathrm{pg} / \mathrm{ml}$ to the cells followed by an incubation at $37{ }^{\circ} \mathrm{C}$ for the indicated periods of time. Subsequently the medium was aspired, the cells were washed once with ice-cold phosphate-buffered saline and rapidly lysed in $300 \mu \mathrm{l}$ of reducing sample buffer $(10 \%$ glycerol, $60 \mathrm{~mm}$ Tris-HCl, pH 6.8, $2 \%$ SDS, $0.3 \mathrm{~m} \beta$-mercaptoethanol, bromphenol blue) followed by shearing (18 gauge needle) and boiling for $10 \mathrm{~min}$. Subsequently, 50- $\mu$ l aliquots were resolved by SDS-polyacrylamide gel electrophoresis $(12.5 \%)$, and the proteins were transferred to nitrocellulose membranes. Filters were first blocked for $1 \mathrm{~h}$ in TBS-T (20 mM Tris-HCl, pH 7.5, $0.15 \mathrm{M} \mathrm{NaCl}$, and $0.05 \%$ Tween 20 ) containing $5 \%$ milk powder and subsequently probed with a rabbit polyclonal antibody directed against p42 MAPK (a gift from Dr. J. L. Bos, University of Utrecht, The Netherlands) in TBS-T supplemented with $1 \%$ milk powder, as described (24). Bands representing phosphorylated and unphosphorylated MAPK were visualized following incubation with mouse-anti-rabbit-linked horseradish peroxidase (Nordic, Tilburg, the Netherlands) by using enhanced chemiluminescence reagent (ECL, Roche Molecular Biochemicals). Finally MAPK bands were quantified to determine the percentage of phosphorylated MAPK. Experiments were repeated at least three times.

ErbB-1 Receptor Tyrosine Phosphorylation-Cells were grown to confluence in 24-well dishes ( $1.8 \mathrm{~cm}^{2}$; Nunc) and subsequently incubated for $24 \mathrm{~h}$ in serum-free medium. Growth factors to be tested were added at various concentrations for $10 \mathrm{~min}$ at $37^{\circ} \mathrm{C}$. After three rapid washes at $4{ }^{\circ} \mathrm{C}$ in calcium and magnesium-free phosphate-buffered saline, cells were lysed by incubation for $10 \mathrm{~min}$ in $100 \mu \mathrm{l}$ of ice-cold radioimmune precipitation assay buffer ( $150 \mathrm{~mm} \mathrm{NaCl}, 50 \mathrm{~mm}$ Tris-HCl, $\mathrm{pH} 7.4,1 \%$ Nonidet P-40, 0.25\% deoxycholate, 1 mu EGTA, 1 mm phenylmethylsulfonyl fluoride, $1 \mathrm{~mm} \mathrm{Na} \mathrm{VO}_{4}, 1 \mathrm{~mm} \mathrm{NaF}, 1 \mu \mathrm{g} / \mathrm{ml}$ aprotinin, $1 \mu \mathrm{g} / \mathrm{ml}$ leupeptin, $1 \mu \mathrm{g} / \mathrm{ml}$ pepstatin). Lysates were cleared by centrifugation ( 5 $\min , 13,000 \mathrm{rpm}$ at $4{ }^{\circ} \mathrm{C}$ ), after which $20 \mu \mathrm{l}$ of $6 \times$ concentrated reducing sample buffer was added to the supernatant. Following SDS-polyacrylamide gel electrophoresis (8\%) and transfer of the proteins to nitrocellulose, blots were washed four times for $15 \mathrm{~min}$ in TBS-T and then blocked by incubation for $1 \mathrm{~h}$ in TBS-T containing $5 \%$ milk powder. Subsequently blots were incubated overnight at $4^{\circ} \mathrm{C}$ in a $1: 5000$ dilution of anti-phosphotyrosine monoclonal antibody (Upstate Biotechnology, Lake Placid, NY) in TBS-T containing 1\% milk powder. After another four washes for $15 \mathrm{~min}$ in TBS-T and a 1-h incubation in TBS-T containing 5\% milk powder, blots were incubated for $2 \mathrm{~h}$ at $4{ }^{\circ} \mathrm{C}$ in a 1:4000 dilution of goat-anti-mouse-linked horseradish peroxidase (Nordic, Tilburg) in TBS-T with $1 \%$ milk powder, followed by four washes for 15 min in TBS-T and visualization using enhanced chemiluminescence reagent.

Ligand Association and Dissociation Experiments-Cells were grown to confluence in gelatinized 24 -well dishes $\left(1.8 \mathrm{~cm}^{2}\right.$; Nunc) and placed on ice. For ligand association experiments, the medium was aspired and replaced by $100 \mu \mathrm{l}$ of ice-cold HEPES-buffered Dulbecco's modified Eagle's medium supplemented with $10 \%$ newborn calf serum (binding buffer) containing $10 \mathrm{ng} / \mathrm{ml}{ }^{125}$ I-labeled mEGF or the chimera E4T. After the indicated time intervals at $4{ }^{\circ} \mathrm{C}$, the medium was removed, and the cells were rinsed twice with ice-cold phosphate-buffered saline, $0.1 \%$ bovine serum albumin and once with ice-cold phosphate-buffered saline. Cells were then lysed by adding $250 \mu \mathrm{l}$ of $1 \%$ Triton X-100 $(\mathrm{v} / \mathrm{v}) /$ well followed by a 1 -h incubation at room temperature prior to $\gamma$-counting. For ligand dissociation experiments, cells were incubated for $2 \mathrm{~h}$ on ice with iodinated ligand $(60 \mathrm{ng} / \mathrm{ml})$ to saturate ErbB-1 binding, then washed twice with ice-cold binding buffer, and subsequently incubated at $4{ }^{\circ} \mathrm{C}$ for the indicated time intervals in $500 \mu \mathrm{l}$ of binding buffer now containing $2 \mu \mathrm{g} / \mathrm{ml}$ unlabeled ligand. Subsequently cells were washed, lysed, and analyzed for ligand binding as described above for the ligand association experiments. Independent experiments were carried out twice with similar results.

Surface Plasmon Resonance Experiments and Data Analysis-The cDNA of the extracellular domain of the human epidermal growth factor receptor (EGFR-ED) was cloned and expressed using baculovirus-infected Sf9 cells as described previously (25). Soluble EGFR-ED was purified using a mild nonaffinity, two-step ion exchange chromatography procedure (26), quantitated in an enzyme-linked immunosorbent assay according to Grimaux et al. (27), and was found to contain at least $85 \%$ pure EGFR-ED based a densitometric scanning of Coomassie Blue-stained $12 \%$ SDS-polyacrylamide gel. For SPR experiments (BIAcore 1000, Uppsala, Sweden), EGFR-ED was cross-linked to the flexible dextran matrix of a CM5 sensor chip using the EDC/NHS coupling method by injecting the following reagents $(30 \mu \mathrm{l})$ at a flow rate of 5 $\mu \mathrm{l} / \mathrm{min}$ : $0.05 \mathrm{M} N$-hydroxysuccinimide, $0.2 \mathrm{M} N, N$-(3-dimethylaminopropyl)- $N$-ethyl-carbodiimide mixture, EGFR-ED $(15 \mu \mathrm{g} / \mathrm{ml}$ in $10 \mathrm{~mm}$ $\mathrm{NaAc}, \mathrm{pH} 5.0$ ), and $1 \mathrm{~m}$ ethanolamine-HCl ( $\mathrm{pH}$ 8.5). Typical immobilizations of EGFR-ED resulted in a signal reaching between 4000 and 6000 resonance units. Experiments were carried out at room temperature using three different EGFR-ED purifications and various sensor chips, using at least one flow cell treated in a similar manner but in the absence of EGFR-ED as a control for each chip.

For kinetic experiments various dilutions of the ProtA-tagged EGF, $\mathrm{TGF} \alpha$, or chimeras thereof with calibrated biological activity were prepared in HEPES-buffered saline (150 mM NaCl, $3.4 \mathrm{~mm}$ EDTA and 10 mM HEPES, pH 7.4) supplemented with $0.05 \%$ Polysorbate 20 (BIAcore, Uppsala, Sweden). Samples were subsequently injected for a period of 3 min (flow rate $5 \mu \mathrm{l} / \mathrm{min}$ ) into a flow cell containing either immobilized EGFR-ED or a control surface. Surfaces were successfully regenerated up to 50 times by acid treatment ( $5 \mathrm{~mm}$ acetic acid, $135 \mathrm{~mm} \mathrm{NaCl}, 2.5$ $\mathrm{mm} \mathrm{KCl}, \mathrm{pH} 2.5$ ) to remove bound ligand, as described previously (8, 20). Generated sensorgrams were analyzed using the integrated rate equations in the BIAevaluation 2.1 software. The association rate constant $\left(k_{\text {on }}\right)$ and the dissociation rate constant $\left(k_{\text {off }}\right)$ were determined directly from the wash-on and the wash-off phase over a 10-s period, starting at 5 and $185 \mathrm{~s}$, respectively, after the start of the wash-on phase, based on single exponent kinetics for both phases. In addition, the dissociation equilibrium constant $K_{D}$ was determined directly from the plateau values in the sensorgrams using Scatchard analysis. 


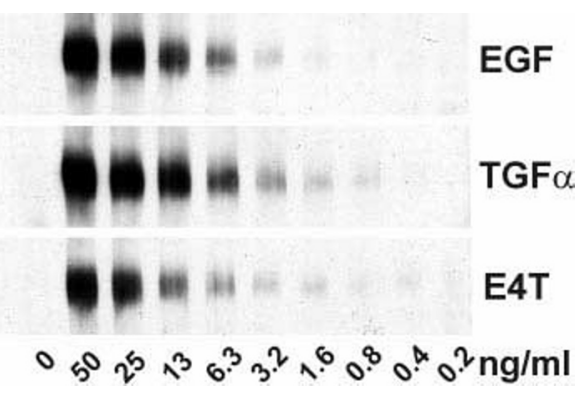

FIg. 1. Dose-dependent tyrosine phosphorylation of ErbB-1 induced by hEGF, hTGF $\alpha$, and E4T. HER-14 cells were incubated for $10 \mathrm{~min}$ at $37^{\circ} \mathrm{C}$ with the indicated concentrations of ligand. From the cellular protein $10 \mu \mathrm{g}$ was loaded onto SDS-polyacrylamide gel electrophoresis and phosphorylation of the 170-kDa ErbB-1 receptor was visualized by probing with anti-phosphotyrosine antibodies.

\section{RESULTS}

ErbB-1 Receptor Tyrosine Phosphorylation by EGF/TGF $\alpha$ Chimeras - In a previous study we have shown that chimeras of hEGF and hTGF $\alpha$, obtained by exchanging domains bordered by their conserved cysteine residues, all have similar binding affinity for ErbB-1 (23). In the nomenclature used, a chimera such as E4T stands for a ligand with hEGF sequences $\mathrm{N}$-terminal and hTGF $\alpha$ sequences C-terminal of the fourth cysteine (19). Three of those chimeras, designated E3T, E4T, and T3E4T, have been shown to induce mitogenic activation of ErbB-1-containing cells at a 10-fold lower concentration than the wild-type growth factors EGF and $\mathrm{TGF} \alpha$, indicating their superiority in activating this receptor (20). These three superagonistic chimeras have also been shown to induce ErbB-1 recycling after ligand-induced internalization, similar to $\mathrm{TGF} \alpha$, but unlike EGF and other nonsuperagonistic chimeras tested (20). Moreover, studies using cells with defined combinations of ErbB receptors have indicated that this superagonistic behavior can be fully ascribed to activation of ErbB-1 receptors and is not the consequence of specificity in the formation of ErbB receptor heterodimers (10).

To investigate if the superagonistic behavior of these chimeras correlates with an enhanced induction of intracellular second messengers, we first compared the ability of the superagonist $\mathrm{E} 4 \mathrm{~T}$ and the wild-type ligands EGF and TGF $\alpha$ to induce ErbB-1 receptor tyrosine phosphorylation in HER-14 cells in a dose-dependent manner. Fig. 1 shows that a near similar dose dependence of ErbB-1 tyrosine phosphorylation for all three ligands following 10 min of treatment, with a detection limit of $1-3 \mathrm{ng} / \mathrm{ml}$ and an estimated half-maximum effect in the order of $10-20 \mathrm{ng} / \mathrm{ml}$ ligand. Receptor phosphorylation levels remained constant between 2 and 60 min after ligand addition. Equal loading on the gel was verified by reprobing the blot with anti-ErbB1 antibodies (not shown). No shift to lower concentrations could be observed for the superagonist E4T, as previously shown for the dose dependence of mitogenic activity (20). The concentrations required here for the induction of receptor tyrosine phosphorylation are of the same order of magnitude as those required for binding of these EGF-like ligands to ErbB-1 $\left(K_{D}=10-20 \mathrm{ng} / \mathrm{ml}\right.$; Ref. 23$)$ but are at least 10-100-fold higher than the concentrations required for half-maximal mitogenic stimulation $(0.1 \mathrm{ng} / \mathrm{ml}$ for E4T and $1 \mathrm{ng} / \mathrm{ml}$ for EGF and TGF $\alpha$; see Ref. 20).

Mitogen-activated Protein Kinase Activation by EGF/TGF $\alpha$ Chimeras-The MAPK family members p42 and p44 are rapidly phosphorylated upon activation of ErbB receptors by both Ras and protein kinase C-mediated pathways (24). Previous work from our group has shown a direct correlation between MAPK activation and mitogenic activity of EGF-like growth factors (15). To obtain more insight in the kinetics of receptor

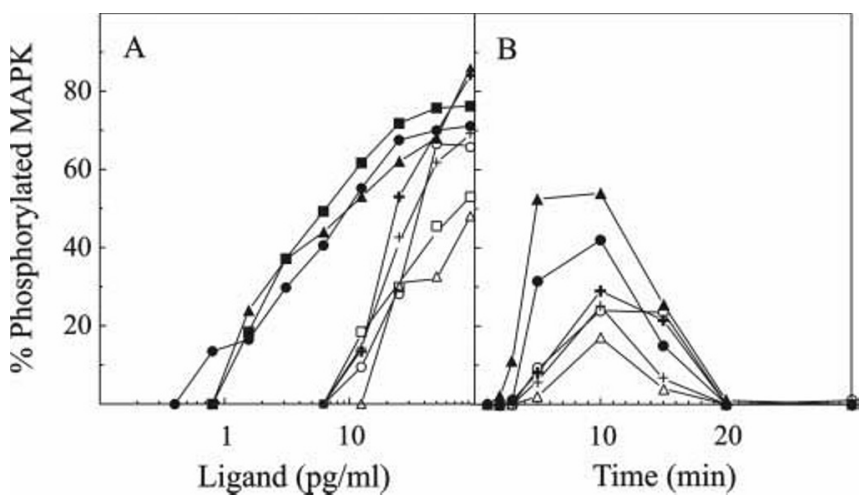

FIG. 2. Dose- and time-dependent phosphorylation of MAPK in HER-14 cells. Confluent serum-starved cells were incubated with serial dilutions of hEGF (+), hTGF $\alpha(+), \mathrm{E} 3 \mathrm{~T}(\quad), \mathrm{T} 3 \mathrm{E}(\mathrm{O}), \mathrm{E} 4 \mathrm{~T}(\mathbf{\Delta}), \mathrm{T} 4 \mathrm{E}$ $(\triangle)$, E3T4E $(\square)$, or T3E4T (ם) for 5 min at $37^{\circ} \mathrm{C}(A)$ or with a fixed concentration of $10 \mathrm{pg} / \mathrm{ml}$ of these various ligands for the indicated periods of time at $37^{\circ} \mathrm{C}(B)$. MAPK phosphorylation was then determined as described under "Experimental Procedures."

activation, we compared the dose and time dependence of MAPK phosphorylation by the superagonistic chimeras to those of the other EGF-like ligands. Fig. $2 A$ shows MAPK phosphorylation in HER-14 cells 5 min after the addition of serial dilutions of both wild-type ligands or chimeras. MAPK phosphorylation induced by nonsuperagonistic ligands was observed at concentrations above $10 \mathrm{pg} / \mathrm{ml}$, whereas $50 \mathrm{pg} / \mathrm{ml}$ was required to obtain a level of 50\% phosphorylated MAPK. However, in the case of the three superagonists, phosphorylated MAPK was already observed at $1 \mathrm{pg} / \mathrm{ml}$, with a $50 \%$ phosphorylation level at $5 \mathrm{pg} / \mathrm{ml}$. Fig. $2 B$ represents a time course of MAPK phosphorylation in HER-14 cells upon the addition of a fixed concentration $(10 \mathrm{pg} / \mathrm{ml})$ of recombinant growth factors. Compared with the other ligands tested, the superagonists E3T and E4T clearly showed a higher level and a more rapid onset of MAPK phosphorylation. Regardless of the nature and concentration of the ligand used, the induction of MAPK phosphorylation appeared to be a transient event in these cells, because we were unable to detect any phosphorylated MAPK upon incubations longer than 20 min (see Fig. $2 B$ ).

These results regarding MAPK phosphorylation closely match the differences observed in the mitogenic activity of the various chimeric ligands (20). Taking into account the low ligand concentrations and short time intervals used in this study, it seems unlikely that the observed differences in MAPK phosphorylation result from altered routing of the receptor after ligand-induced internalization. As will be discussed they can well be explained, however, if the superagonists show an enhanced rate of receptor binding, which allows them to activate the receptor more rapidly than the wild-type ligands.

The Receptor Binding Kinetics of the Superagonists Differ from Those of the Wild-type Ligands-To directly test the receptor association and dissociation kinetics of this set of EGF/ $\mathrm{TGF} \alpha$ chimeras, the time course for binding of radiolabeled mEGF at $4{ }^{\circ} \mathrm{C}$ was compared with that of the superagonist E4T. Indeed, Fig. $3 A$ shows that ${ }^{125} \mathrm{I}-\mathrm{E} 4 \mathrm{~T}$ binds more rapidly to the cells than ${ }^{125} \mathrm{I}-\mathrm{mEGF}$, at a similar concentration. Interestingly, Fig. $3 B$ shows that dissociation of ${ }^{125} \mathrm{I}-\mathrm{E} 4 \mathrm{~T}$ from its receptor is also more rapid than for ${ }^{125} \mathrm{I}-\mathrm{EGF}$, indicating that superagonists may have both enhanced association and dissociation rate constants when compared with wild-type ligands. The apparent values for the association and dissociation rate constants of the two ligands obtained from this experiment are indicated in the legend to Fig. 3.

Protein A-tagged Ligands Behave Similar to Nontagged Ligands-SPR is a powerful technique for real time analysis of 


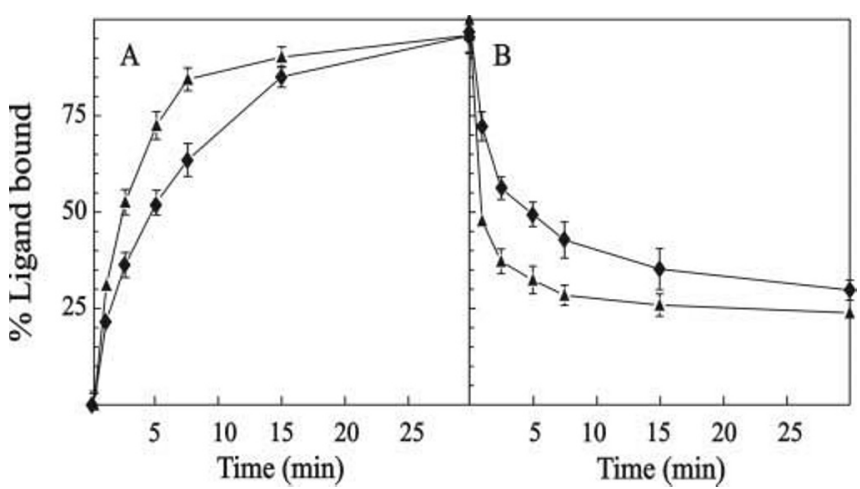

FIG. 3. Association (A) and dissociation $(B)$ curves for cellular binding of iodinated mEGF $(\diamond)$ and E4T $(\Delta)$ at $4{ }^{\circ} \mathrm{C}$. Association curves were obtained using $10 \mathrm{ng} / \mathrm{ml}$ labeled ligand (specific activity: $1.8 \times 10^{5} \mathrm{cpm} / \mathrm{ng}$ for $\mathrm{mEGF}$ and $1.2 \times 10^{5} \mathrm{cpm} / \mathrm{ng}$ for E4T), whereas dissociation curves were obtained by monitoring the release of receptorbound labeled ligand in the presence of $60 \mathrm{ng} / \mathrm{ml}$ unlabeled ligand. Estimated parameters from these curves are: $k_{\mathrm{on}} \mathrm{EGF}=1.0 \times 10^{6} \mathrm{M}^{-1}$ $\mathrm{s}^{-1} ; k_{\text {off }} \mathrm{EGF}=0.003 \mathrm{~s}^{-1} ; k_{\text {on }} \mathrm{E}_{4} \mathrm{~T}=1.7 \times 10^{6} \mathrm{M}^{-1} \mathrm{~s}^{-1} ; k_{\text {off }} \mathrm{E}_{4} \mathrm{~T}=0.008$ $\mathrm{s}^{-1}$.

the association and dissociation characteristics of ligand binding. Changes in mass resulting from the interaction of a ligand with a specific binding protein immobilized on the dextran matrix of a BIA-core sensor chip can be measured directly by this technique (28). However, EGF-like growth factors have a molecular size of $\sim 6 \mathrm{kDa}$, and therefore changes in the resonance signal as a result of their binding to an immobilized receptor molecule are difficult to detect $(29) .{ }^{2}$ The recombinant growth factors used in this study have originally been expressed as ProtA fusion proteins with a molecular size of 20 $\mathrm{kDa}$. To test if such ProtA-tagged ligands could be used in SPR experiments, we first tested if they show similar superagonistic characteristics as their HPLC purified derivatives without tag.

Fig. $4 A$ shows that ProtA-tagged EGF/TGF $\alpha$ chimeras are biologically active in that they compete with ${ }^{125} \mathrm{I}$-mEGF for binding to HER-14 cells. By superpositioning of the various competition curves to that of unlabeled mEGF, the amount of mEGF binding equivalents was determined for each of the chimeras. Fig. $4 B$ shows the mitogenic response of HER-14 cells upon the addition of known concentrations of mEGF binding equivalents of the various ProtA-tagged chimeras. Fusion proteins of E3T, E4T, and T3E4T showed half-maximal mitogenic response at a concentration of $\sim 0.1 \mathrm{ng} / \mathrm{ml}$ binding equivalents, whereas the other ligands including hEGF and $\mathrm{hTGF} \alpha$ required almost $1 \mathrm{ng} / \mathrm{ml}$ binding equivalents for half-maximal stimulation. This demonstrates that the above superagonists maintain their enhanced potency also when N-terminally tagged to other proteins.

Surface Plasmon Resonance Analysis of Receptor Binding Kinetics of EGF/TGF $\alpha$ Chimeras-To measure the association and dissociation kinetics for binding of EGF/TGF $\alpha$ chimeras to ErbB-1 by real time analysis, the soluble extracellular domain of this receptor (EGFR-ED) was covalently linked to the flexible dextran matrix of a CM5 sensor chip. Subsequently various concentrations of the ProtA-tagged ligand corresponding to known binding equivalents were injected. Fig. 5 shows typical sensorgrams obtained for the wild-type ligands hEGF and $\mathrm{hTGF} \alpha$, in comparison with the nonsuperagonistic chimera T4E and the superagonist E4T. Even in the absence of a numeric analysis it can be seen that the sensorgrams for EGF, $\mathrm{TGF} \alpha$, and T4E are very similar, whereas that of E4T shows enhanced kinetics of both receptor association and dissociation. Table I gives a survey of the association $\left(k_{\text {on }}\right)$ and dissociation

${ }^{2}$ A. E. G. Lenferink and M. D. O’Connor-McCourt, unpublished data.

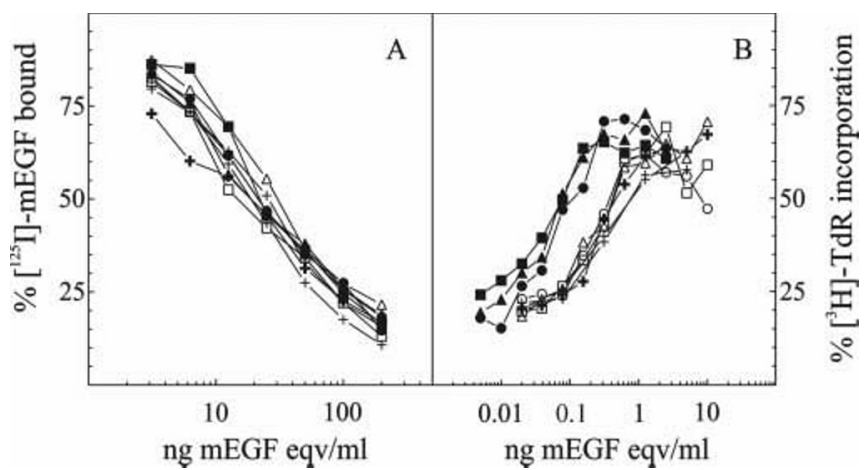

FIG. 4. Inhibition of ${ }^{\mathbf{1 2 5}}$ I-mEGF binding and mitogenic stimulation of protein A-tagged EGF-like ligands to HER-14 cells. The binding activity $(A)$ of ProtA-tagged hEGF $(+), \operatorname{hTGF} \alpha(+)$, E3T ( ), T3E $(\bigcirc)$, E4T $(\Delta)$, T4E $(\triangle)$, E3T4E $(\square)$, and T3E4T $(\square)$ was calibrated to give a similar competition for binding of iodinated mEGF to HER-14 cells as natural mEGF. Concentrations of ErbB-1 binding activity calculated from these curves are expressed in ng mEGF eq $/ \mathrm{ml}$. With these calibrated concentrations the mitogenic activity $(B)$ of ProtA-tagged

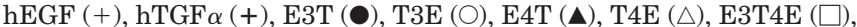
and T3E4T ( $)$ was tested. This was assessed by measuring $\left[{ }^{3} \mathrm{H}\right]$ thymidine $(T d R)$ incorporation in serum-starved HER-14 cells $24 \mathrm{~h}$ after growth factor addition. Radioactivity incorporation in the presence of $10 \%$ newborn calf serum was determined at $(2.97 \pm 0.03) \times 10^{5} \mathrm{cpm} /$ well, while in the absence of added growth factor cells incorporated $(16.25 \pm 1.80) \%$ of this value. Data are presented as the representative curves of experiments that were carried out in duplicate and repeated twice.
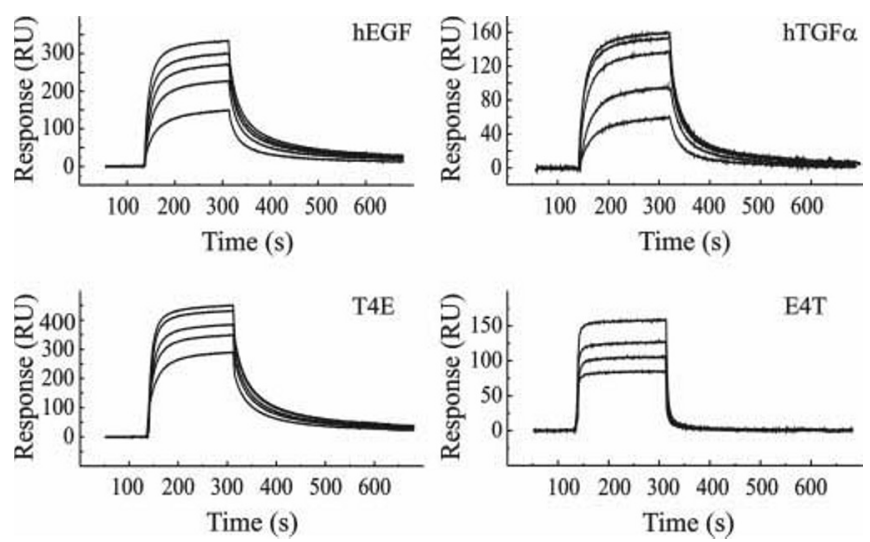

FIG. 5. Real time binding data of the interaction of protein $A$ fusion proteins of EGF-like ligands to dextran matrix-immobilized EGFR-ED. The interaction of the various fusion proteins with EGFR-ED was plotted in resonance units $(R U)$ as a function of time. Sensorgrams represent the interaction of ProtA-hEGF (20, 40, 60, 80, and $100 \mathrm{~nm}$ EGF eq.), ProtA-hTGF $\alpha$ (10, 20, 30, 40, and $50 \mathrm{~nm} \mathrm{EGF} \mathrm{eq.),}$ ProtA-T4E $(20,40,60,80$, and 100 nm EGF eq.), and ProtA-E4T (40, 60, 80 , and $100 \mathrm{~nm}$ EGF eq.). The $k_{\text {on }}$ and $k_{\text {off }}$ values were calculated by fitting the data of the association and dissociation phases to a single exponential. Equilibrium binding constants $\left(K_{D}\right)$ were determined directly from the ratio of these two parameters and in addition from the plateau values using Scatchard analysis. Kinetic values are presented in Table I. Sensorgrams are shown from a typical experiment, which was repeated at least five times with similar results.

$\left(k_{\text {off }}\right)$ rate constants of the superagonists and a number of nonsuperagonistic EGF/TGF $\alpha$ chimeras determined from analysis of these sensorgrams. A single exponential fit was carried out on both the association and dissociation phase and subsequently a value for the dissociation equilibrium constant $K_{\mathrm{D}}$ was determined according to $k_{\text {off }} / k_{\text {on }}$. A second value for $K_{D}$ was obtained directly from the resonance values at equilibrium according to a Scatchard analysis. The present data show that all three superagonists (E3T, E4T, and T3E4T) have enhanced values of both $k_{\text {on }}$ and $k_{\text {off }}$ when compared with the nonsuperagonists tested. In contrast, the $K_{D}$ value determined from the ratio of both parameters is not significantly different for the 
TABLE I

Binding constants of $N$-terminally protA-tagged EGF, TGF $\alpha$, and chimeras thereof on immobilized EGFR-ED

The $k_{\text {off }}$ value was calculated directly from the wash off phase at each ligand concentration by fitting to a single exponent according to $R=R_{0}$. $\exp \left(-k_{\text {off }} \times\left(t-t_{0}\right)\right)$. The $k_{\text {on }}$ value was calculated by fitting the association kinetics for each ligand concentration $C$ to $R=R_{\text {eq }} \times\left(1-\exp \left(-\left(k_{\text {on }}\right.\right.\right.$ $\left.\left.\times C+k_{\mathrm{off}}\right) \times\left(\mathrm{t}-t_{\mathrm{o}}\right)\right)$. Kinetic analysis was performed using the BIA-evaluation software 2.1. Scatchard analysis was performed on a plot $R_{\mathrm{eq}} / \mathrm{C}$ versus $R_{\text {eq. }}$ ND, not determined because no proper scatchard plot could be obtained; S.E., standard error of the mean. The number of experiments are in parentheses.

\begin{tabular}{|c|c|c|c|c|c|c|}
\hline & $k_{\text {off }}^{a}$ & $\mathrm{SE}$ & $k_{\mathrm{on}}^{b}$ & S.E. & $K_{D}^{c}$ & $K_{D}^{d}$ \\
\hline & $s^{-1}$ & & $10^{6} \times M^{-1} \times s^{-1}$ & & $n M$ & $n M$ \\
\hline hEGF (14) & 0.03 & 0 & 1.63 & 0.02 & 21 & 23 \\
\hline $\mathrm{hTGF} \alpha(13)$ & 0.04 & 0 & 2.08 & 0.37 & 19 & ND \\
\hline $\mathrm{E} 3 \mathrm{~T}(5)$ & 0.09 & 0.01 & 4.17 & 1.15 & 22 & ND \\
\hline T3E (5) & 0.04 & 0 & 1.15 & 0.02 & 34 & 61 \\
\hline $\mathrm{E} 4 \mathrm{~T}(5)$ & 0.21 & 0.03 & 5.54 & 0.56 & 38 & 26 \\
\hline $\mathrm{T} 4 \mathrm{E}(6)$ & 0.04 & 0.01 & 2.27 & 0.44 & 19 & 29 \\
\hline E3T4E (6) & 0.04 & 0 & 1.76 & 0.06 & 22 & 41 \\
\hline T3E4T (6) & 0.09 & 0.01 & 5.06 & 0.08 & 18 & 21 \\
\hline
\end{tabular}

${ }^{a}$ The association rate constant $\left(k_{\mathrm{on}}\right)$ is shown.

${ }^{b}$ The disassociation rate constant $\left(k_{\text {off }}\right)$ is shown.

${ }^{c}$ The disassociation equilibrium constant $\left(K_{D}\right)$ determined from the above constants according to $K_{D}=k_{\text {off }} / k_{\text {on }}$ is shown.

${ }^{d}$ The disassociation equilibrium constant $K_{D}$ from scatchard analysis is shown.

superagonists. Also the $K_{D}$ value directly determined from the sensorgrams according to Scatchard analysis is very similar for all ligands tested, which is in agreement with previous binding data on intact cells (23). The observation that the enhanced ability of superagonistic EGF/TGF $\alpha$ chimeras to induce MAPK phosphorylation is paralleled by faster receptor association kinetics may play an important role in the mechanism underlying the superagonistic behavior of these three ligands.

\section{DISCUSSION}

Polypeptide growth factors are generally well characterized by their receptor binding affinity, but more and more evidence is accumulating that receptor binding characteristics are not the sole determinants for their signaling potency. We have previously characterized three EGF/TGF $\alpha$ chimeras (E3T, E4T, and T3E4T) that show superagonistic activity despite the fact that they have similar $K_{D}$ values for binding to ErbB-1 as the wild-type ligands EGF and $\mathrm{TGF} \alpha$ (19). Here we show that this superagonistic behavior is paralleled by enhanced MAPK phosphorylation but not by enhanced receptor tyrosine phosphorylation. Moreover, using in vitro receptor binding studies and surface plasmon resonance measurements, we show that this superagonistic activity is paralleled by enhanced kinetics of both ligand association and dissociation to the ErbB-1 receptor.

Generation of second messengers such as receptor tyrosine phosphorylation and MAPK phosphorylation takes place within minutes after growth factor addition to ErbB-1 receptors, often even before equilibrium binding to the receptor has taken place. The time required for reaching equilibrium binding strongly depends on the ligand concentration added, because the receptor binding association rate is not only proportional to the association rate constant $k_{\text {on }}$ but also to the applied ligand concentration. The experiment in Fig. $3 A$ shows that upon addition of $10 \mathrm{ng} / \mathrm{ml}$ ligand, equilibrium binding requires between 10 and 15 min when measured at $4{ }^{\circ} \mathrm{C}$. Measurements of receptor tyrosine phosphorylation $10 \mathrm{~min}$ after addition of more than $10 \mathrm{ng} / \mathrm{ml}$ of ligand at $37^{\circ} \mathrm{C}$ are therefore carried out under conditions of near equilibrium binding and therefore primarily reflect the ligand's $K_{D}$ value, which is similar for all ligands tested in the present study. In the MAPK experiments, however, 1000-fold lower concentrations are used, which are beyond the detection limit of the receptor tyrosine phosphorylation assay. Under these conditions, receptor occupation after $10 \mathrm{~min}$ will still be far from equilibrium, and the observed differences between the various ligands will mainly reflect their $k_{\text {on }}$ values. Because complete MAPK phos- phorylation is observed also at these low ligand concentrations, it has to be concluded that only a fraction of available ErbB-1 receptors has to be occupied for activation of the signal transduction pathways leading to MAPK phosphorylation. EGF can induce MAPK phosphorylation in these cells by both a phospholipase C- $\gamma$ and a Ras-mediated pathway (24), but we have not established the contribution of these individual pathways in the present study. The mitogenic response appears to require intermediate concentrations of ligand although in long term incubations, but interestingly it reflects more the observed differences in association and dissociation rate constants than in $K_{D}$ value. In agreement with the above considerations, the data of Figs. 2 and 4 show that the superagonistic and the nonsuperagonistic EGF/TGF $\alpha$ chimeras become equally potent in the mitogenic assay and the MAPK assay when tested at concentrations above $10 \mathrm{ng} / \mathrm{ml}$.

It is well established that after ligand-induced internalization, the EGF-ErbB-1 complex is degraded in the lysosomes, whereas the TGF $\alpha$-ErbB-1 complex dissociates and recycles to the plasma membrane (8). We have previously shown that the three superagonists tested here mimic $\mathrm{TGF} \alpha$ in their ability to induce ErbB-1 recycling, whereas all other nonsuperagonistic chimeras induce receptor degradation similar to EGF (20). $\mathrm{TGF} \alpha$ has no superagonistic activity in the assays used in this study, suggesting that receptor recycling after ligand-induced internalization may be essential but not sufficient to explain the superagonistic character of various EGF/TGF $\alpha$ chimeras. Moreover, previous data have shown that the rate of ligandinduced receptor internalization is similar for the superagonists and the nonsuperagonistic chimeras (20), although it is well realized that those studies have been performed at concentrations (100 ng/ml) high above the range required for MAPK phosphorylation and mitogenic activation. It has been suggested elsewhere that an enhanced $k_{\text {off }}$ of a ligand could cause a more potent mitogenic response because the ligand is less efficiently depleted from the medium (18). It will require more detailed investigations on ErbB-1 internalization and ligand degradation induced by EGF, TGF $\alpha$, and the superagonists (10) to establish a causal relation between the mitogenic activity of these ligands and their receptor binding on and off rates.

In previous plasmon surface resonance measurements on EGF-receptor interaction, Zhou et al. (29) have studied the binding of the soluble extracellular domain of ErbB-1 (EGFRED) to covalently cross-linked EGF. The use of a similar approach in the current study would require the optimization of 
cross-link conditions for each individual EGF/TGF $\alpha$ chimera. The approach used in the present study requires only a single immobilization method to cross-link EGFR-ED to the sensor chips. The sensitivity problem in detecting resonance differences as a result of binding of small ligand molecules was solved by using ProtA-tagged growth factors with an overall molecular size of $20 \mathrm{kDa}$. It is well realized that binding of EGF-like growth factors to the immobilized EGFR-ED is not necessarily a reflection of their binding characteristics to intact cellular ErbB-1. Soluble EGF receptors and their extracellular domains, either prepared as recombinant protein or as purified secretion product of A431 cells, have a binding affinity that is at least one order of magnitude lower than that of membranelinked EGF receptors (30). Furthermore it is not clear if crosslinked EGFR-ED provides the same opportunity for ligandinduced receptor dimerization as is present on intact cells. A numeric comparison of the data of Fig. 3 and Table I shows that the $K_{D}$ values of the various EGF-like growth factors tested are approximately 10 -fold higher in the plasmon surface resonance measurements than upon binding to intact cells, mainly as a result of a similarly enhanced dissociation rate constant. Particularly in the case of the superagonists, accurate determination of $k_{\text {off }}$ by SPR analysis has been made difficult by the very rapid ligand dissociation. However, the sensorgrams shown in Fig. 5 clearly indicate that at all concentrations tested the superagonist E4T has enhanced dissociation kinetics, indicating that the resulting higher value of $k_{\text {off }}$ is an intrinsic property of this type of ligand. Furthermore in the analysis of our data we used two different approaches to calculate the $K_{D}$ values of the various mutants and found that the values obtained satisfied the internal self-consistency requirements proposed by Schuck and Minton (31). Scatchard analysis on the resonance values at equilibrium did not only yield a $K_{D}$ value but also a parameter for the ligand binding capacity. For reasons that are currently not well understood, maximum binding of the three superagonists reached only $25-50 \%$ of the levels observed for EGF and other nonsuperagonists (data not shown). Nonetheless, this could be indicative for a different binding stoichiometry of the superagonists to the extracellular domain of the EGF receptor immobilized on the sensor chips.

It is currently not known what structural aspects of the above three EGF/TGF $\alpha$ chimeras determine their superagonistic character. Their relatively high histidine content has been associated with their enhanced $\mathrm{pH}$ dependence of binding and concomitantly with their ability to induce receptor recycling after ligand-induced internalization (20). However, in this aspect the superagonists do not differ from $\mathrm{TGF} \alpha$, and it also provides no explanation why these molecules have at the same time enhanced association and dissociation kinetics. Structural analysis of these superagonists may provide a molecular basis for these observations, and could indicate if molecules could be designed in which $k_{\text {on }}$ and $k_{\text {off }}$ can be altered independently from each other. We have recently shown that a chimera of EGF and the Drosophila EGF receptor antagonist Argos has a 20 -fold lower binding affinity for human ErbB-1 as wild type EGF. Still this chimera is almost as potent as EGF in inducing MAPK phosphorylation and mitogenic activation of HER-14 cells (15). This suggests that the rate of MAPK phosphorylation may be a better reflection of a ligand's mitogenic potential than its receptor binding affinity. It could therefore be hypothesized that a more intense receptor signaling is induced by a ligand that in a dynamic manner is rapidly associating and dissociating, than by a ligand that is more or less irreversibly attached to its receptor. Subsequent experiments will have to indicate how such dynamic parameters can influence ErbB-1 activation by taking into account their effects on depletion of the ligand by receptor-mediated internalization and the subsequent routing of the internalized receptor.

Acknowledgments-We are grateful to Dr. Th. J. Benraad and J. J. T. M. Heuvel (Department of Experimental and Chemical Endocrinology, University Hospital Nijmegen) for radiolabeling mEGF and E4T, and to Dr. J. L. Bos (Laboratory of Physiological Chemistry, University of Utrecht) for anti-MAPK antibodies.

\section{REFERENCES}

1. Yarden, Y., and Ullrich, A. (1988) Annu. Rev. Biochem. 57, 443-478

2. Moolenaar, W. H., Bierman, A. J., Tilly, B. C., Verlaan, I., Defize, L. H. Honegger, M., Ullrich, A., and Schlessinger, J. (1988) EMBO J. 7, 707-710

3. Alroy, I., and Yarden, Y. (1997) FEBS Lett. 10, 83-86

4. Prigent, S. A., and Lemoine, N. R. (1992) Prog. Growth Factor Res. 4, 1-24

5. Riese, D. J., and Stern, D. F. (1998) Bioessays 20, 41-48

6. Bergeron, J. J., Di Guglielmo, G. M., Baass, P. C., Authier, F., and Posner, B. I. (1995) Biosci. Rep. 15, 411-418

7. Vieira, A. V., Lamaze, C., and Schmid, S. L. (1996) Science 274, 2086-2089

8. Ebner, R., and Derynck, R. (1991) Cell Regul. 2, 599-612

9. Baulida, J., Kraus. M. H., Alimandi, M., Di Fiore. P. P., and Carpenter, G. (1996) J. Biol. Chem. 271, 5251-5257

10. Lenferink, A. E., Pinkas-Kramarski, R., van de Poll, M. L., van Vugt, M. J., Klapper, L. N., Tzahar, E., Waterman, H., Sela, M., van Zoelen, E. J., and Yarden, Y. (1998) EMBO J. 17, 3385-3397

11. Waterman, H., Alroy, I., Strano, S., Seger, R., and Yarden, Y. (1999) EMBO J. 18, 3348-3358

12. Keresztes, M., and Boonstra, J. (1999) J. Cell Biol. 145, 421-424

13. Kimura, H. (1993) Proc. Natl. Acad. Sci. U. S. A. 90, 2165-2169

14. Walker, F., Nice, E., Fabri, L., Moy, F. J., Liu, J. F., Wu, R., Scheraga, H. A., and Burgess, A. W. (1990) Biochemistry 29, 10635-10640

15. Van de Poll, M. L., van Vugt, M. J., Lenferink, A. E., and van Zoelen, E. J. (1997) Biochemistry 36, 7425-7431

16. Van de Poll, M. L., van Vugt, M. J., Lenferink, A. E., and van Zoelen, E. J. (1998) J. Biol. Chem. 273, 16075-16081

17. Puddicombe, S. M., Wood, L., Chamberlin, S. G., and Davies, D. E. (1996) J. Biol. Chem. 271, 30392-30397

18. Reddy, C. C., Niyogi, S. K., Wells, A., Wiley, H. S., and Lauffenburger, D. A. (1996) Nature Biotechnol. 14, 1696-1699

19. Kramer, R. H., Lenferink, A. E., van Bueren-Koornneef, I. L., van der Meer, A., van de Poll, M. L., and van Zoelen, E. J. (1994) J. Biol. Chem. 269, $8708-8711$

20. Lenferink, A. E., Kramer, R. H., van Vugt, M. J., Konigswieser, M., Di Fiore, P. P., van Zoelen, E. J., and van de Poll, M. L. (1997) Biochem. J. 327, 859-865

21. Honegger, A., Dull, T. J., Szapary, D., Komoriya, A., Kris, R., Ullrich A., and Schlessinger, J. (1988) EMBO J. 7, 3053-3060

22. Van Zoelen, E. J., Kramer, R. H., van Reen, M. M., Veerkamp, J. H., and Ross, H. A. (1993) Biochemistry 32, 6275-6280

23. Van de Poll, M. L., Lenferink, A. E., van Vugt, M. J., Jacobs, J. J., Janssen, J. W., Joldersma, M and van Zoelen, E. J. (1995) J. Biol. Chem. 270, $22337-22343$

24. Burgering, B. M., de Vries-Smits, A. M., Medema, R. H., van Weeren, P. C. Tertoolen, L. G., and Bos, J. L. (1993) Mol. Cell. Biol. 13, 7248-7256

25. Brown, P. M., Debanne, M. T., Grothe, S., Bergsma, D., Caron, M., Kay, C., and O'Connor-McCourt, M. D. (1994) Eur. J. Biochem. 225, 223-233

26. Debanne, M. T., Pacheco-Oliver, M. C., O'Connor-McCourt, M. D. (1995) Methods Mol. Biol. 39, 349-361

27. Grimaux, M., Laine-Bidron, C., and Magdelenat, H. (1989) Tumour Biol. 10, $215-224$

28. Johnsson, B., Lofas, S., and Lindquist, G. (1991) Anal. Biochem. 198, 268-277

29. Zhou, M., Felder, S., Rubinstein, M., Hurwitz, D. R., Ullrich, A., Lax, I., and Schlessinger, J. (1993) Biochemistry 32, 8193-8198

30. Kohda, D., Odaka, M., Lax, I., Kawasaki, H., Suzuki, K., Ullrich, A. Schlessinger, J., and Inagaki, F. (1993) J. Biol. Chem. 268, 1976-1981

31. Schuck, P., and Minton, A. P. (1996) Trends Biochem. Sci. 21, 458-460 